\title{
Infertility in India: social, religion and cultural influence
}

\author{
Poonam Sheoran*, Jyoti Sarin
}

Faculty of Nursing, Maharishi Markendeshwar University, Mullana, Ambala, Haryana, India

Received: 29 September 2015

Revised: 01 October 2015

Accepted: 17 October 2015

\section{*Correspondence:}

Poonam Sheoran,

E-mail: principalmmin@mmumullana.org

Copyright: (c) the author(s), publisher and licensee Medip Academy. This is an open-access article distributed under the terms of the Creative Commons Attribution Non-Commercial License, which permits unrestricted non-commercial use, distribution, and reproduction in any medium, provided the original work is properly cited.

\begin{abstract}
Background: Society, culture and religion frame the major sphere of life for human kind since starting. Fertility has been one of man's desired attributes since the beginning of recorded history and remains a driving need for young couples today. Infertility, however, continues to be a major worldwide problem, affecting an estimated 60-80 million women and men, a vast majority of whom live in low resource countries. The aim of the study was to assess the living-in experiences of infertile women under social and religional and cultural influence.

Methods: This was a phenomenological study conducted at Infertility clinic of Haryana, India. Data was collected was semi structured interview guide and face to face in depth interviews. Participants were selected using criterion sampling technique and data saturation was achieved after 22 interviews. All interviews were audiotaped using a digital recorder.

Results: The findings of the study showed that three main themes related to social, religious and cultural influence with core theme of Environmental influence of their infertility experience.

Conclusions: The study concluded that there is a huge burden on the part of female to have a baby after marriage. Also the childless women face social and financial adversities at time and this is not limited to low income or low education strata. Health care professionals need to understand cultural and social implications of infertility in order to provide counseling, and referring women with fertility concerns for consultation and further treatment.
\end{abstract}

Keywords: Infertility, Phenomenology, Qualitative, Social influence, Religion influence, Cultural influence

\section{INTRODUCTION}

To procreate had been cherished dream of mankind since long. Couples start dreaming about their future life with kids' immediately after marriage or in some cases after some time. Not all couples succeed in starting a family when they wish for it and couples in India also face difficulties related to reproduction. Based on the census reports of India for 2001, 1991 and 1981 researchers show that infertility in India has increased by 50 percent since 1981. The Marital infertility rate has gone up from 11 to 16 percent. ${ }^{1}$ The WHO estimates the overall prevalence of primary infertility in India to be between 3.9 to 16.8 percent. $^{2}$ Research studies quote that $25 \%$ of total couples suffering with infertility are in India alone. ${ }^{3}$
As per DLHS 3 survey in India around $8.8 \%$ of currently married women in reproductive age group had infertility problems, with wide variation ranging from $14 \%$ to $3 \%$. At the national level, around $6 \%$ women have primary infertility where as $2 \%$ have secondary infertility. ${ }^{4}$

Since ancient times, many Indian couples have suffered from infertility and have gone to great lengths to have a baby. Infertility touches all aspects of affected couples life. However in India, infertility is a particularly important problem since it is associated with specific social, cultural and religious aspects stemming from the long and varied history of the country and the importance of religion in the life of all Indians. In most areas of the women's wellbeing is reported to be more affected by 
infertility then men. In developing countries position of women is defined by their reproductive capacity and their failure to do so due to any reason leads to social and cultural repercussions for them. Women express consistently lower scores on mental health, social functioning and emotional behaviour domains in quality of life and experience higher levels of stigma than men. ${ }^{5,6}$

\section{METHODS}

Present paper has been originated from the doctorate study conducted by author. The Study investigated the living in experience of infertility among married women of Haryana with respect to how they describe, make meaning in terms of social, psychological, physical, financial, marital and sexual construct and how they cope with it. In addition this study investigated the medical and conventional methods used by infertile women as treatment. This paper highlights the social, cultural and religious aspects of infertility experienced by women in northern part of India. Qualitative research approach with Hermeneutic phenomenology design was used. Data was collected with face to face in depth interviews using semi structured interview guide from infertile women with primary infertility attending OPD of selected infertility clinic. Participants were selected using criterion sampling technique and data saturation was achieved after 22 interviews. All interviews were audiotaped using a digital recorder. Participants were encouraged to express their experiences freely and without any restriction. Length of interview lasted from $45 \mathrm{~min}$ to 70 minutes. Interviews were conducted from January 2014 to August 2014. All interviews were conducted in IVF clinic only. A contact summary was made at the end of each interview to summarize the main points.

\section{Ethical consideration}

Ethical approval for the study was taken from institutional ethical committee of the Maharishi Markandeshwar University. To protect the identity of the participants, confidentiality of the research data was maintained through the use of pseudonyms for all the participants interviewed. All women consented in writing to participate in study. All audiotapes and transcriptions of the participants were numbered Recorded interviews and transcriptions along with consent forms were kept in locked cabinet. Each participant was explained about outline of whole research and their right to withdraw from study at any time.

\section{Validity}

Validity of data was ensured using Creswell's (2007) validation techniques. Researcher used rich, thick descriptions to describe in detail the experiences of participants. Expert panel views were incorporated as research progress reports were presented before departmental research committee. Researcher professional experience in Obstetrics and Gynecology area ensured prolonged engagement with infertile women. As a part of external audit, codes, subthemes and themes were discussed and analysed by two colleagues. Each of them independently coded interviews. As a group, themes were studied and examined, challenged among each other and made adjustment. Apart from this a record of all transcription and field notes were kept for external audit. Finally, a cross checking of the whole analysis process was done by the research supervisor.

\section{RESULTS}

Demographic findings of the participants revealed mean age of participants was 29.68 (23-40 yrs.). Educational status ranged from being illiterate to Master's degree with two (02) participants being illiterate and six (06) with Master's degree. Maximum (19) number of participants were house wives where as two (02) of them teacher by profession and one (01) was working as counsellor. Mean duration of marriage among participants was 8.4 yrs. (324 yrs.) and mean duration for trying for conception was 7.92 yrs. (1 yr. 9 months-24 yrs.). Cause of infertility was unknown for 06 participants whereas 14 were diagnosed with female cause of infertility and 02 with male cause.

\section{Themes}

During the data analysis three main themes along with 10 subcategories emerged. Main core theme was environmental influence. Three subthemes which were identified were 1) Influence of Society, 2) Influence of religion and 3) Influence of Culture. Below, the meaning of each theme is presented by using the participants' direct quotations.

\section{Influence of society}

All participants described the message and beliefs they have received from the society regarding infertility. Society seems to influence the experiences of women with infertility. The way they perceive importance of motherhood depends a great deal on the societal messages and beliefs. This subtheme comprised of four categories as (i) Blame from society, (ii) Social pressure to conceive, (iii) remarriage of husband and (iv) reputation in society.

\section{Blame from society}

In Indian society, infertility is taken as women's problem and she is blamed for not able to procreate. As a dutiful wife she is expected to start a family immediately after marriage and when fails to do so, she is blamed for her role failure and often subjected to negative remarks and blame from in laws and neighbors. Infertile women are often subjected to words like MANHOOS, VANJH (barren), possessing evil eye and visiting to tantric (person performing black magic). A young infertile woman of 23 yrs. reported to undergo various invasive procedures (hysterosalpingogram) just to satisfy her 
family and herself that there is no problem with her so that nobody can blame her for infertility.

"like this only time will pass...tomorrow nobody should say that there is some problem in girl.. nobody should blame....everybody in family told me not to get tube test (hysterosalpingogram) done.. but still I underwent it... as I have to satisfy myself and my family that there is no problem in me.." (P8)

Women also expressed to be blamed for the expenditure which occurred on treatment mostly by their mother in law.

"mother in law says...whole savings of my son goes in your treatment....she taunts.. $i$ listen... what else can I do??" (P12)

This blaming from the society takes its toll on physical and psychological wellbeing of women and they shared how a talk with neighbour or some relative becomes a matter of tension and stress for them and this constant blaming leave them drained emotionally and physically. As shared by one woman:

"at times it happens 10 -15 days pass happily and then on 16th day something of this kind happens that all past 15 days also goes in waste.. whatever energy I had gained.. that is lost because somebody will say something" (P2)

\section{Social pressure to conceive}

Family is the most important social entity in India. After marriage young bride moves to husband's home and often live with his family sometimes even extended family. The family and relatives of husband plays an important role in couple's life. When a women is not able to conceive family and even neighbours become involved in the couple's lives and put more pressure on women by asking again and again and suggesting remedies or treatment outlets. As one participant shared:

"I feel there is so much of social pressure on me to conceive.. And this pressure is more from my family as compared to outside.... there is pressure from every side and that why I am not able to do or concentrate at all...." (P14)

Another one said:

"we never thought having baby so soon, but with everyone's suggestion we started trying... every one ask what happened.... what is the problem...cousin of my husband got married recently and now she is 5 month pregnant.. so now everyone says.. (P4)

Women also feel pressurized seeing other of same age with their children. They expressed feeling more pressure to conceive if somebody of same age in family or friends conceives or delivers a child, she is considered as next person to give good news naturally.

\section{Fear of remarriage of husband}

Motherhood is considered a power for the new bride and lack of which makes her vulnerable. For men, remarriage is the most commonly mentioned solution, based on the belief that women are the source of infertility. Though majority of participants shared to have a supportive husband but they also expressed constant fear of husband's remarriage under social pressure.

"even though my husband refuses for second marriage now but who knows he may change his mind later on..... his thinking is good at present...but you never know...time changes everything....it may happen like 99\% I believe he will not change but 1\% I fear he may change with time $(P 4)$

Quite often, partner who is carrying infertility can ask her spouse to find another partner, so that he can experience fatherhood. Women often are pressurized for second marriage of their husband.

"yes...there is trend of second marriage..... family members pressurize husband and wife...... wife will be emotionally blackmailed ..like I am there...after 2- 4 yrs. perhaps same thing will be there with me as well... I will be expected to prepare my husband for remarriage stating that don't I want his clan to expand.. dont I want him to be happy??" (P5)

Being fertile becomes a base for continuation of marriage and infertile woman especially with diagnosed female cause of infertility is more subjected to threat of husbands remarriage

"I do fear about his second marriage..(kahi mujhe chod naa de..) this is last chance to save my marriage... if I am not able to conceive now. $i$ wont able to remain married then..." (P22)

\section{Reputation in society}

Women with infertility are considered less than others as they are not able to fulfil predesigned role of female as approved by society. Participants reported to feel as second citizen in comparison to those who enjoy fertility as expressed by one:

"there are girls who cannot cook, they don't have anything.. don't respect their husband.. but just because they have babies they are respected.. and in us only because of this problem all our good qualities are side lined....we might have everything but that is not visible to people.. they are not able to see those..." (P4) 


\section{Influence of religion}

Second subtheme under influence of environment emerged as influence of religion. All participants at some or other time during interview expressed their believe in God and majority of them quoted their struggle to their past karmas (deeds). Two subcategories under this theme are 1) faith in God 2) game of destiny.

\section{Faith in God}

In India, religion has a strong influence of life. Many beliefs and values related to procreation are embedded in daily life and originate from holy books and ancient stories. GOD is considered as creator and HE only can give life.

Many of the participants reported that they accept infertility as the wish of God and that they have full faith in God.

"I believe in God...have faith.. he will help me.. whatever problem is there will be solved.." (P13)

"I think it is God's wish...otherwise I was completely well...." (P4)

"now I have left everything on God...whenever he feels He would give.." (P7)

Even one explained about being blessed with everything in life and is hopeful on seeing at others who cannot even afford to get a treatment done.

"I am very thankful to God that he has blessed me with so many things...I can get treatment of my choice...there are many who cannot do so...my servant also is also having infertility since last 15 yrs.... her husband drinks.... when I see her life.. i thank God... there is day night difference between me and her... I still feel hopeful... perhaps GOD will bless.. Doctors are doing their task.. but at the end God only has to bless..." (P6)

Two of the participants reported turning spiritual spiritual and performing of certain rituals as these believed to gain GOD's blessings.

"have turned spiritual.... do lots of pooja.. have asked for blessings everywhere.."(P13)

\section{Game of destiny}

Apart from God, a person's own deeds also believed to decide course of life. Participants believed that the struggle which they are dealing might be the result of their past karmas. Likewise they mentioned:

"its my destiny only that after so much of medicines also I am not able to conceive.." (P21)
"I blame destiny for this.......... I pray even my enemies should not face this...God do not do this even with my enemies" (P5)

One of the participant even mentioned that infertility in present birth is the result of bad karmas done by her in the past.

"don't know... I might not have done good karma in my last birth... now I try not to hurt anyone... not to disturb any one... so that means this is the result of our past birth... we are getting punishment of that now.." (P6)

\section{Influence of culture}

Third subtheme under influence of environment emerged as influence of culture. India is a patriarchal society which considers male to be the head of family. He is considered as superior and all decision making power lies with him or other elders in family. Under influence of culture experiences of infertile women were categorized under 3 subcategories (i) Cost of treatment to be born by girls parents, (ii) decision making,(iii) burden of male infertility.

\section{Cost of treatment to be borne by girls' parents}

Under this sub category women shared their experiences of being subjected to humiliation and lack of finances. If cause of infertility comes out to be female factor, women's parents are supposed to bear the burden of cost of treatment. It may be noted that these experiences were more profoundly experienced by women who belonged to low socioeconomic status with poor education.

"my mother in law father in law says we cannot afford your treatment... you go back to your home and get yourself treated.... they have started taunting me.. (P22)

"my parents are helping me out now... my brother and bhabi are very nice... they are giving money now..." (P12)

\section{Decision making}

In Patriarchal culture a women is supposed to submissive and must agree to the decisions taken by her husband in order to prove herself as a dutiful wife. Newly married women are not entitled to take major decisions regarding her life. As here participants expressed:

"I think I should do something in my profession.. but then nobody in family allow that no...your treatment is going on...don't try anything now.. if only I had been unmarried.. $i$ would have touched new heights.. even if want to start some work related to my profession as I have so much time my husband say don't do this all...." (P8) 
Treatment seeking is also decided by family members and if it is not as per their choice, couple is not allowed to go for it. A male partner cannot have any problem and medical examination of him becomes a family issue.

"when doctor suggested to get my husbands tests done.. my mother in law got angry.. why you got his tests done? Then there was some problem with his reports.. so doctor gave medicines.. which cost us of few thousand.. but my mother in law did not allowed him to take and got all medicines returned..." (P4)

\section{Burden of male infertility}

In terms of infertility male infertility carries bigger stigma and his virility is questioned. Male is supposed to be masculine and capable of producing. Male infertility brings a question to his capability as a men and threat to him related to his responsibility to carry family lineage.

One participant shared her experience of carrying burden of her husbands' infertility:

\begin{abstract}
"My husband does not want to talk about it...even though I want to share my feelings with him. But don't say anything with fear that he may feel I am blaming him....i have not disclosed it to anyone but that adds up my burden...so many times neighbours ask me and I have to pretend that I have some problem because of which I am not able to conceive...so many times my mother in law taunts me in front of others regarding not giving her grandchildren... but I cannot say anything to her...have to hear everything...have to undergo all this pain alone..(sobs) (P 18)
\end{abstract}

\section{DISCUSSION}

The findings of this study provide insight in the influence of environment on experience of infertile women in North India. Studies have shown that infertile women face systemic, societal level stigmatization. In our study also participants reported facing social blame for their inability to conceive and being targeted for her role failure. These findings are consistent with other Asian studies of where women explained facing rude inquiries regarding their fertile capabilities and being termed as 'Manhoos', inauspicious and bearer of bad luck. ${ }^{8,9}$ In present study participants expressed feeling of social pressure to conceive. Couples are pushed to have children as soon as possible and remedies and treatment suggestions are bombarded from all sides on young wife. In India if a child is not conceived quickly, couples face pressure and stigma from their family and community. ${ }^{10}$ In some cases relatives, mostly from the husband part, have frequent contacts with the women and this makes the pressure even worst for them. ${ }^{11,12}$ Participants also expressed threat of second marriage of husband owing to their inability to provide a heir to his family and at time wives are expected to get their husbands remarry. These findings are consistent with the findings of studies where infertile women indicated that getting their husband remarry could be only solution to overcome their social adversities and remarriage was most common mentioned solution of infertility. ${ }^{8,13}$ Responses of the participants also showed that they feel as second citizens and others consider them less than other even if they are talented. Same feeling are echoed in findings of study where infertile women shared that child gives respect and honour to women in eyes of in laws. ${ }^{14}$

Religion played a significant role in influencing the experiences of women and shaping their outlook towards disease. In Hindu mythology GOD is considered as creator and HE only can bless with life. Deeds of past either in this birth or last birth and destiny play a significant role in shaping a person's present. Studies conducted in India and Iran also showed that infertile women believed in a supreme power, accepted their infertility as God's will and result of their karmas of last birth. ${ }^{8,14,15}$ where as in another study infertile women reported having lost faith in God due to struggle of infertility. ${ }^{16}$

Participants in present study shared lack of financial support from in laws and no power of decision making which is similar to other study in South Asia where infertile women did not get proper care, refusal of food and clothing, abuse from husband and in laws and have to consult mother in law for treatment options. ${ }^{8}$ New bride has to prove her worth via her fertility and until she does that, she remains at weak position in house hold. Male infertility attracts greater stigma and cannot be disclosed. Women only are expected to bear the burden and endure the pain of social blame and pressure. Even if husband is infertile, a woman in Jorden reported to endure this feeling on behalf of their husband and bears the consequences of being infertile and social ehaviours. ${ }^{13}$

\section{CONCLUSIONS}

To conclude, in Indian society a baby is of great significance and having a baby has religious implications. When a couple is childless, women are explicitly held responsible. Because of social norms an infertile female have lesser status and prestige in society and may be subjected to refusal of fulfilling of basic needs in extreme cases. Male infertility puts a question on virility of men and questions masculinity, hence is kept under cover. Women face social and financial adversities at time and this is not limited to low income or low education strata. Study recommends use of IEC (information, education and communication) strategies at community level to decrease stigma attached with infertility. Health care professionals need to understand cultural and social implications of infertility in order to provide counselling, treatment and referring women with fertility concerns for consultation and further treatment. 


\section{ACKNOWLEDGEMENTS}

Researchers sincerely express their gratitude to all the participants for willingly participating in this study and providing us the opportunity to know about the experiences related to infertility.

Funding: No funding sources

Conflict of interest: None declared

Ethical approval: Ethical approval taken from Institutional Ethical Committee of Maharishi Markendeshwar University, Mullana, Amabla, India

\section{REFERENCES}

1. Tripathi N. Infertility among Indian Women: Emerging Evidence and Need for Policy Measures, presented at the annual conference of the population Association of America, 2011.

2. Singh P, Shukla U. Inability to conceive and treatment seeking behavior in Uttar Pradesh state in India. Canadian Studies in Population. 2015;15:1-12.

3. Prasad R. Infertility and Treatment Seeking Behavior among women of EAG states in India. India 2014: Population and Development. 87-10

4. Unisa S. Infertility and treatment seeking in India. Findings from District level house hold survey. Facts, Views \& Vision in Ob Gyn. 2010:59-65

5. El Kissi Y, Amamou B, Hidar S, Ayoubi Idrissi et al. Quality of life of infertile Tunisian Couples and difference According to Gender. International journal of Gynaecology and Obstetrics. 2014;125(2);134-7.

6. Wischmann T, Scherg H, Stowitzki T. Psychosocial characteristics of women and men attending infertility Clinic. Human Reproduction. 2009;24(2):378-85.

7. Creswell JW. Qualitative inquiry and research design: choosing among five traditions (2nd edition), 2007.

8. Papreen N, Sharma A, Sabin K, Begum L, Ahsan K $\mathrm{S}$, et al. Living with infertility: experiences among urban slum populations in Bangladesh. Reproductive Health Matters. 2000;8(15):33-44.

9. Mumtaz Z, Shahid U, Levay A. Understanding the impact of gendered roles on the experiences of infertility amongst men and women in Punjab. BMC Reproductive Health. 2013;10(3).

10. Barua A, Apte H, Pande R, Walia S. Infertility concerns among young couples in rural India Available at http://www.researchgate.net/publication/265042162_ Infertility_Concerns_among_Young_Couples_in_Ru ral_India. Accessed on 02.08.2015

11. Tahiri FB, Kalaja D, Bimbashi EK. The Lived Experience of female Infertility: The Case of Muslim Rural Women Leaving in Albania. European Scientific Journal. 2015;11(11):268-77.

12. Wiersema NJ, Drukker AJ, Dung MBT, Nhu GH, Nhu NT et al. Consequences of infertility in developing countries: Results of a survey in the south of Vietnam. Journal of Translational Medicine. 2006;4:54.

13. Obeisat S, Gharaibeh KM, Oweis A, Gharaibeh H. Adversities of Being Infertile: The experience of Jordanian Women. Fertility and Sterility. 2012;98(2):444-9.

14. Mishra K, Dubey A. Indian Women's Perspective on Reproduction and Childlessness: Narrative Analysis. International Journal of Humanities and Social Sciences. 2014;4(6):157-14.

15. Roudsari LR, Allan HT. Women's experience and Preferences in Relation to infertility counseling: A multi faith Dialogue. International Journal of Fertility and Sterility. 2011;5(3):158-67.

16. Berger R, Marilyn S, Henshaw LA. Women's Experience of infertility: A multi systemic Perspective. Journal of International Women's Studies. 2013;14(1):54-68.

Cite this article as: Sheoran P, Sarin J. Infertility in India: social, religion and cultural influence. Int J Reprod Contracept Obstet Gynecol 2015;4:1783-8. 